\title{
Commentary on Using Systematic Case Studies to Investigate Therapist Responsiveness: Examples from a Case Series of PTSD Treatments
}

\section{Case Studies Help Us Read Between the Lines of Manual-Driven Therapy}

\author{
TRACY D. EELLS ${ }^{\text {a,b }}$ \\ ${ }^{\mathrm{a}}$ Department of Psychiatry and Behavioral Sciences, University of Louisville \\ b Correspondence concerning this article should be addressed to Tracy D. Eells, Department of Psychiatry and \\ Behavioral Sciences, University of Louisville, 401 East Chestnut Street, Suite 610, Louisville, KY 40202 \\ Email: eells@louisville.edu
}

\begin{abstract}
Edwards' (2010) article illuminates the benefits of systematic case series analysis in exploring metacompetencies such as therapist responsiveness. These benefits are unique contributions of systematic case analyses since the situational and temporal contexts provided by cases are lost in group comparison research such as randomized clinical trials. For this reason, the two approaches triangulate well with each other, in the sense described by Edwards. Aggregation of findings from multiple cases facilitates generalization. Edward's systematic case series of PTSD treatments demonstrates one important and pragmatic way in which this generalization can be accomplished. I discuss Edward's approach to studying therapist responsiveness in light of methodology, theory-building, training, and case formulation.
\end{abstract}

Key words: case studies; case study series; metacompetencies; therapist responsiveness; posttraumatic stress disorder (PTSD); randomized clinical trials (RCTs)

Edwards' (2010) article illustrates how analysis of a series of systematic case studies can illuminate critical therapeutic processes occurring in manual-based therapies. These phenomena, which he organizes under the general rubric of therapist responsiveness, might otherwise go unrecognized or undervalued. As Edwards notes, therapist responsiveness is a broad concept, but one that captures the essential idea of the therapist engaging with the client's psychological states as they appear in the therapy sessions. At a broad level, responsiveness also includes planning treatment and selecting a clinical focus in accord with these states. The relationship between responsiveness and treatment planning was well captured in an entirely different context by Dwight D. Eisenhower who observed, "Plans are nothing; planning is everything." That is, the therapist benefits from planning with the assistance of a treatment manual, a model guiding his or her clinical focus, and a case formulation, but the therapist must also respond to the immediate needs and psychological states of the client, shifting course as warranted. Edwards emphasizes that the flexibility needed to be responsive must be balanced by staying within a form of treatment that has been demonstrated to be efficacious. A case study analysis allows one 
to see the interplay between responsiveness and the requirements of the manual. A series of case study analyses illustrates the many forms that this interplay can take.

In this commentary, I will discuss some specific ways that the contextualized perspective offered by case series analysis and as described by Edwards can contribute to psychotherapy research, practice, and training. These ways include contributions to research methodology, theory building, supervision of psychotherapists in training, and the case formulation process.

\section{CONTRIBUTIONS OF CASE SERIES ANALYSIS TO METHODOLOGY}

Edwards points out methodological issues that arise from the inevitable variability in the manner by which a manual-based therapy is delivered. Manuals and associated measures of treatment adherence were developed to standardize therapy. Without assurance that all patients in a treatment arm of a randomized clinical trial (RCT) receive essentially the same therapy, one cannot draw conclusions about that form of therapy. However, as Edwards discusses, therapy manuals vary in the detail to which the prescribed therapy is described. Many details may either be implicit or may be described in general terms, such as "tailor the prescribed treatment as needed to the individual client." Examples of these unarticulated details include selection of a clinical focus, timing of interventions, responding to a lack of compliance on the part of the client, establishing and maintaining a therapeutic relationship, and communicating warmth on the part of the therapist.

Importantly, all the above examples illustrate a need for appropriate responsiveness on the part of the therapist and may play a crucial role in determining the therapy outcome, as a review of the cases Edwards describes suggests. The case of Bongi perhaps captures this point best because the case was particularly complex. Although the prescription of Ehlers and Clark (2000) that the client re-experience the traumatic memory and then re-evaluate associate appraisals and triggers was accomplished, Bongi clearly did not "follow the script" of the ideal patient. She was evasive and vague at times, unpredictable, had multiple problems that were both current and longstanding, continued to engage in unwise sexual behavior during therapy, was suicidal at times, became easily angered, had many mood and affect shifts that threatened the therapy, and was slow to establish a stable, trusting relationship with the therapist. Nevertheless, the therapist used the clinical focus framework and exercised considerable empathy and flexibility to maintain a high degree of responsiveness and thereby guided Bongi to a point where she was willing to relive one of the rapes. Her tolerance for these reliving experiences was also managed in a metacompetent fashion, to the extent that Bongi was eventually able to use the experience productively. As presented in the paper, the therapist's responsiveness to Bongi's presenting conditions allowed him to join with her appropriately while also remaining within the broad framework of a manualized therapy that has demonstrated strong efficacy. The combination of the RCT and the case study provided for a comprehensive view of the phenomena and the factors that led to treatment success. It does lead one to wonder, however, about where the boundaries lie between adhering to the manual and exercising therapeutic responsiveness. Perhaps there are core elements to manualized treatment such that, if those elements are missing, one should not claim to have provided that form of therapy. 
I agree with Edwards' point that systematic case studies are uniquely suitable for exploring phenomena "between the lines" of the therapy manual, as illustrated in the case of Bongi. I also share the view that deriving principles from such studies and finding ways to test and refine them is a major challenge for researchers. Edwards notes some attempts, such as the application of principles of "case law" (Bromley, 1986), a triangulation strategy in which results from different methods or perspectives are independently examined, and applying systematic criteria for assessing the trustworthiness of qualitative research (Lincoln, 2002). Finding points of articulation between systematic case studies and the results of RCTs, which is a variant of triangulation, may be a particularly promising approach. Edwards' approach to systematic case studies is an exemplar of this strategy. Such systematic case studies are stronger when they include the same quantitative measures of process, outcome, adherence, and so on, as those administered in RCTs testing the same diagnosis. Taking this additional step permits a direct linkage between the two methodological contexts (Dattilio, Edwards, \& Fishman, in press). Analyzing selected cases from an RCT could be particularly illuminating. These may include cases that should best exemplify the inferences drawn from the RCT, such as the most improved clients. Alternatively, they may include cases that did not improve, with an analysis of the factors that led to poor outcome. It may turn out that failures in therapist responsiveness contributed to these outcomes. Additionally, developing systematic case studies of randomly selected clients may offer insights into the "typical” client, and help determine whether it makes sense to think in terms of a typical client. In light of the triangulation approach just discussed, a group comparison study could be developed hypothesizing responsiveness as measured by appropriate selection of a treatment focus to be a mediating variable (Baron \& Kenny, 1986; Frazier, Tix, \& Barron, 2004). In general, searching for points of convergence and divergence between the nomothetic literature and results of series of systematic case studies appears to be a promising approach.

\section{CASE SERIES ANALYSIS AS A BASIS FOR THEORY BUILDING}

Edwards’ proposes and explores a model for evidence-based, responsive treatment planning for posttraumatic stress disorder (PTSD). The model holds that issues related to patient safety and crisis stabilization must be adequately addressed initially, as shown in his Level 1 clinical foci. Then, as shown in the Level 2 foci, emphasis shifts to establishing and maintaining a positive therapeutic alliance and to explaining and gaining client acceptance of the treatment model and its underlying rationale. Once the groundwork in Levels 1 and 2 is in place, the therapist can shift to Level 3, which in the case of the Ehlers and Clark (2000) cognitivebehavioral model for posttraumatic stress disorder, involves exposure to the traumatic memories and revision of the associated maladaptive appraisals and triggers. Edwards explains that his model is flexibly sequential in that emphasis could be placed on any level at any point in therapy, but that the major emphasis should be on moving sequentially through the model.

This model could be formally developed as a theory of clinical focus selection and investigated with systematic case studies. Edwards has already taken steps in this direction. He writes that he developed and revised his model as part of his systematic case study project. In doing so, he follows an abduction-like process, as described by Stiles (2009) as part of a logical operation for theory-building based on case studies. Abduction involves revising a theory in 
light of new observations. One proposes a tenet that, if true, would predict the new observation. The tenet must be consistent with other tenets in the theory. A formal process of abduction might be used by Edwards to explore the assumption of sequentiality in his model of clinical focus selection, as well as under what conditions exceptions to the sequentiality assumption might be indicated. These efforts could lead to the development of algorithms for selecting among the clinical foci.

An additional factor in developing theory on the basis of a series of case studies should be to systematically seek out and examine disconfirming evidence, then examine whether one's preferred theory offers the better explanation of the phenomena studied. This method is part of a model proposed by Edelson (1984) as a condition for using case studies to investigate psychodynamic theory. It is an important step since the risk of a confirmation bias is great. The researcher is looking for specific outcomes and processes, and therefore it is easy to confirm their presence and overlook disconfirming evidence.

\section{SYSTEMATIC CASE SERIES IN SUPERVISION}

Edwards' study of responsiveness in the context of the Ehlers and Clark model for PTSD is conducted through systematic case studies in which the therapists are his students and supervisees. As part of this experience, the students write up their clients as systematic case studies. The training implications of this approach strike me as extremely significant. By writing up the training cases in a detailed and systematic way, students must engage in a thoughtful review and reflection of psychopathology and psychotherapy theory and research, and then apply that knowledge to the unique circumstances of a specific individual.

This juxtaposition of nomothetic knowledge with the idiographic case addresses the problem of "inert knowledge” in clinical training as described by Binder (1993). Inert knowledge pertains to the application of knowledge in practice. It is knowledge about theory, facts, principles and concepts that are learned but which are not brought to bear on a practical problem that calls for their application. It is thought that the problem of inert knowledge is related to deficiencies in the manner in which the knowledge is acquired. When acquired in a manner that is decontextualized from situations in which it will be applied, the knowledge becomes difficult to apply when the need arises.

Edward's practice of teaching psychotherapy through systematic case studies may be an excellent antidote to the problem of inert knowledge since it brings declarative knowledge and the context for developing procedural knowledge closely together. My reading of the outstanding full systematic case study of Bongi only added to this supposition (van der Linde, 2007). To the extent that trainees engage in an initial draft of the write up as the case is being treated the greater the benefit is likely to be. The client should benefit from the therapist's considerations of the treatment, and the therapist is able to think through different possible interventions more thoroughly. Treating one case in this detailed and intensive manner would seem more beneficial than treating many more clients in a less systematic way, although that is an empirical question. Edwards appears to have an excellent opportunity to conduct research on his manner of teaching psychotherapy. 
Edward's model for selecting a clinical focus also has implications for training. Along with the case formulation, the model provides an organizing structure to help therapists assess progress of therapy and to select appropriate areas to focus on. My colleagues and I found that having an a priori structure to organize information about clients was more characteristic of expert case formulators than nonexperts (Eells, Lombart, Kendjelic, Turner, \& Lucas, 2005). Edwards' model provides such a structure for treatment planning. It is important to have these organizing structures since clients often do not follow our plan, throw surprises at us, or otherwise do not fit or comply with the case formulation. The structure provides a way for the therapist to orient him or herself and to adjust to what is unfolding in therapy.

\section{CASE FORMULATION AND RESPONSIVENESS}

I conclude with a few remarks about case formulation. Edwards notes that formulation is a metacompetency in that it is an aid to and involves making strategic decisions about where to focus as a case unfolds. He also notes that, in selecting a clinical focus from his model, attention is given to the formulation and to the ongoing monitoring of clients' responses to interventions. A case formulation helps the therapist predict how a client is likely to respond to an intervention and what will elicit strong emotions and be experienced as challenging. Therapist responsiveness contributes to and benefits from a good formulation.

The value and relevance of Edwards' model for focusing clinical attention is not limited to the Ehlers and Clark's treatment model for PTSD. It is readily generalized into a crosstheoretical approach to treatment planning. The general approach of initially ensuring safety and symptom stabilization, and then moving to an explanation of a treatment model and building the therapeutic alliance before emphasizing the elements of a specific treatment approach (i.e., exposure and cognitive re-evaluation in the case of Ehlers and Clark) has been recommended by theorists as diverse as Linehan (Koerner, 2007) and Kernberg (Kernberg, Selzer, Koenigsberg, Carr, \& Appelbaum, 1989) for the treatment of borderline personality disorder. The clinical focus model is also consistent with Frank's idea that providing clients with a plausible rationale for treatment and establishing a relationship in which the therapist is viewed as someone who can help are necessary preconditions for therapeutic success (Frank \& Frank, 1991).

Edwards’ model could readily be incorporated into a general organizational scheme for treatment planning as part of a case formulation. Client safety and symptom stabilization are an appropriate initial focus for any treatment plan for any form of therapy. Specific steps to ensure safety and for containing symptomatic distress sufficient to proceed with treatment could be part of this initial plan. Second, presenting a treatment rationale, including alternative treatments, and developing a therapeutic alliance are a common early focus for many forms of therapy. These foundational steps may be accomplished quickly for many clients, although for others, they may be points where the therapy repeatedly returns. It is in Level 3 of Edwards' model that the distinctive aspects of a specific form of treatment are expressed. These will vary considerably from one form of treatment to another, and the specific goals and planned interventions will vary, as Edwards notes, depending on the entire case formulation. In summary, Edwards offers a model of determining clinical focus that is adaptable to multiple modes of therapy and to multiple diagnoses. 
In this commentary, I have shared my reflections on Edwards' innovative and promising approach to psychotherapy research and training. I agree with him that systematic case studies contextualize therapy in ways that randomized clinical trials cannot, and thus contribute unique knowledge about psychotherapy. Systematic case studies allow one to "read between the lines" of manual-driven therapy by identifying potentially critical processes and choices that may not be delineated in the manual. Multiple case studies are an important component in generalizing findings. Both approaches — systematic case studies and randomized clinical trials - complement each other, each provides distinctive information by design, and together they provide a more comprehensive picture of a treatment approach then either does alone.

\section{REFERENCES}

Baron, R. M., \& Kenny, D. A. (1986). The moderator-mediator variable distinction in social psychological research: Conceptual, strategic, and statistical considerations. Journal of Personality and Social Psychology, 51(6), 1173-1182.

Binder, J. L. (1993). Is it time to improve psychotherapy training? Clinical Psychology Review, 13, 301-318.

Bromley, D. B. (1986). The case study method in psychology and related disciplines. Chichester: John Wiley.

Dattilio, F. M., Edwards, D., \& Fishman, D. B. (in press). Case studies within a mixed methods paradigm: Towards a resolution of the alientation between research and practitioner in psychotherapy research. Psychotherapy.

Edelson, M. (1984). Hypothesis and evidence in psychoanalysis. Chicago: University of Chicago Press.

Edwards, D.J.A. (2010). Using systematic case studies to investigate therapist responsiveness: examples from a case series of PTSD treatments. Pragmatic Case Studies in Psychotherapy, 6(4), Article 3, 255-275. Available: http://hdl.rutgers.edu/1782.1/pcsp_journal

Eells, T. D., Lombart, K. G., Kendjelic, E. M., Turner, L. C., \& Lucas, C. (2005). The quality of psychotherapy case formulations: A comparison of expert, experienced, and novice cognitive-behavioral and psychodynamic therapists. Journal of Consulting \& Clinical Psychology, 73, 579-589.

Ehlers, A., \& Clark, D. M. (2000). A cognitive model of posttraumatic stress disorder. Behaviour Research and Therapy, 38(4), 319-345.

Frank, J. D., \& Frank, J. B. (1991). Persuasion and healing: A comparative study of psychotherapy (3rd ed.). Baltimore, MD: The Johns Hopkins University Press.

Frazier, P. A., Tix, A. P., \& Barron, K. E. (2004). Testing moderator and mediator effects in counseling psychology research. Journal of Counseling Psychology, 51(1), 115-134.

Howard, K. I., Lueger, R. J., Maling, M. S., \& Martinovich, Z. (1993). A phase model of psychotherapy outcome: Causal mediation of change. Journal of Consulting and Clinical Psychology, 61(4), 678-685.

Kernberg, O. F., Selzer, M. A., Koenigsberg, H. W., Carr, A. C., \& Appelbaum, A. H. (1989). Psychodynamic psychotherapy of borderline patients. New York: Basic Books. 
Koerner, K. (2007). Case formulation in dialectical behavior therapy for borderline personality disorder. In T. D. Eells (Ed.), Handbook of Psychotherapy Case Formulation (2nd ed.). New York: Guilford Press.

Lincoln, Y. S. (2002). Emerging criteria for quality in qualitative and interpretive research. In N. K. Denzin \& Y. S. Lincoln (Eds.), The qualitative inquiry reader (pp. 327-345). Thousand Oaks, CA: Sage.

Luborsky, L. (1996). The symptom-context method: Symptoms as opportunities in psychotherapy. Washington, DC: American Psychological Association.

Stiles, W. B. (2009). Logical operations in theory-building case studies. Pragmatic Case Studies in Psychotherapy, Vol. 5(3), Article 2, 9-22. Available: http://hdl.rutgers.edu/1782.1/pcsp_journal

van der Linde, F. (2007). Past trauma, anxious future: A case-based evaluation of the Ehlers and Clark model for PTSD applied in Africa. Unpublished research report for Master's in Clinical Psychology. Grahamstown: Rhodes University. Available at http://eprints.ru.ac.za/1832/ 